\title{
Gemfibrozil-Induced Polyuria
}

\author{
Ashraf OE Ahmed ${ }^{1}$, Edmond Okotcha ${ }^{2}$, Abdul-Hussein Saad ${ }^{2}$ \\ ${ }^{1}$ Hamad Medical Corporation, Department of Medicine, Doha, Qatar \\ 2 Patient First Medical Center affiliated with Beaumont Hospital, Dearborn, Michigan USA
}

Received: 06/04/2021

Accepted: $13 / 04 / 2021$

Published: $27 / 04 / 2021$

How to cite this article: Ahmed AOF, Okotcha E, Saad A. Gemfibrozil-induced polyuria. EJCRIM 2021;8: doi:10.12890/2021_002546..

Conflicts of Interests: The Authors declare that there are no competing interests.

Acknowledgements: We would like to thank the medical staff in Patient First Medical Center for their efforts. Also, I would like to thank the patient for being so co-operative and for his consent to the writing of the report.

This article is licensed under a Commons Attribution Non-Commercial 4.0 License

\section{ABSTRACT}

Gemfibrozil is a lipid-regulating agent used mainly to treat patients with hypertriglyceridaemia, especially those at risk for acute pancreatitis. Like any other pharmacological agent, gemfibrozil has known adverse effects, mainly gastrointestinal, such as cholelithiasis, gallstones, elevated transaminase, and other non-specific symptoms including dyspepsia, nausea and vomiting. Other reported adverse reactions are dizziness and vertigo, myopathy and rhabdomyolysis, angioedema, urticaria and rash. As far as we knew, gemfibrozil does not have urinary tract adverse reactions. In this report, we present a case of polyuria secondary to gemfibrozil with a score of 9 on the Naranjo scale, and a literature review.

\section{LEARNING POINTS}

- Gemfibrozil has known, mainly gastrointestinal, adverse effects.

- We aim to increase awareness of the urinary side effects of gemfibrozil so unnecessary investigations can be avoided.

\section{KEYWORDS}

Gemfibrozil, anti-hyperlipidaemic, urinary side effects, polyuria

\section{INTRODUCTION}

A 63-year-old man on atorvastatin for dyslipidaemia was also started on gemfibrozil because of an elevated lipid profile. He subsequently reported increased urine volume and frequency which resolved after gemfibrozil was stopped.

\section{CASE DESCRIPTION}

A 63-year-old man known to have dyslipidaemia was on atorvastatin. He presented to our clinic for follow-up. He did not have any concerns. His vital signs and physical examination were unremarkable. A lipid panel showed his lipid profile had risen over 8 months (Table 1): his triglycerides had increased from $182 \mathrm{mg} / \mathrm{dl}$ to $241 \mathrm{mg} / \mathrm{dl}$ and cholesterol from $218 \mathrm{mg} / \mathrm{dl}$ to $232 \mathrm{mg} / \mathrm{dl}$. He was started on gemfibrozil 600 $\mathrm{mg}$ along with lifestyle modification counselling. After 2 weeks, the patient returned to the clinic with a concern of increasing urine volume and frequency of up to 15 times a day. He associated his symptoms with the new medication (gemfibrozil) as his symptoms had begun 2 days after it was started and had stopped after it was paused for 5 days. He restarted the drug, and when the same symptoms recurred, he returned to the clinic to switch his new drug. The patient denied fever, burning micturition or change in urine colour, and had no flank or groin pain. The review of systems was unremarkable except for increasing fluid intake as he was feeling thirsty because of excessive urination. 
Urine analysis was normal. Other common causes of polyuria were ruled out (Table 2). The patient was reassured, and the gemfibrozil was switched. We assumed that his condition was secondary to gemfibrozil.

\begin{tabular}{|l|l|l|l|}
\hline Measurement & Value & $\mathbf{8}$ Months earlier & Normal value \\
\hline Cholesterol & $232 \mathrm{mg} / \mathrm{dl}$ & $218 \mathrm{mg} / \mathrm{dl}$ & $100-199 \mathrm{mg} / \mathrm{dl}$ \\
\hline Triglycerides & $241 \mathrm{mg} / \mathrm{dl}$ & $182 \mathrm{mg} / \mathrm{dl}$ & $<150 \mathrm{mg} / \mathrm{dl}$ \\
\hline HDL cholesterol & $38 \mathrm{mg} / \mathrm{dl}$ & $38 \mathrm{mg} / \mathrm{dl}$ & $40-90 \mathrm{mg} / \mathrm{dl}$ \\
\hline LDL cholesterol & $146 \mathrm{mg} / \mathrm{dl}$ & $144 \mathrm{mg} / \mathrm{dl}$ & $<100 \mathrm{mg} / \mathrm{dl}$ \\
\hline Non-HDL cholesterol & $194 \mathrm{mg} / \mathrm{dl}$ & $180 \mathrm{mg} / \mathrm{dl}$ & $<130 \mathrm{mg} / \mathrm{dl}$ \\
\hline
\end{tabular}

Table 1. Lipid profile.

HDL, high-density lipoprotein; LDL, low density lipoprotein; VLDL, very low-density lipoprotein.

\begin{tabular}{|l|l|l|}
\hline Measurement & Value & Normal value \\
\hline WBC & $9,400 / \mu l$ & $4-11,000 / \mu l$ \\
\hline Haemoglobin & $16.1 \mathrm{~g} / \mathrm{dl}$ & $13.6-17.6 \mathrm{~g} / \mathrm{dl}$ \\
\hline Creatinine & $1.03 \mathrm{mg} / \mathrm{dl}$ & $0.6-1.3 \mathrm{mg} / \mathrm{dl}$ \\
\hline GFR & $90 \mathrm{ml} / \mathrm{min} / 1.73 \mathrm{~m}^{2}$ & $>60 \mathrm{~mL} / \mathrm{min} / 1.73 \mathrm{~m}^{2}$ \\
\hline Sodium & $143 \mathrm{mmol} / \mathrm{l}$ & $135-145 \mathrm{mmol} / \mathrm{l}$ \\
\hline Potassium & $4.2 \mathrm{mmol} / \mathrm{l}$ & $3.5-5.3 \mathrm{mmol} / \mathrm{l}$ \\
\hline Glucose & $79 \mathrm{mg} / \mathrm{dl}$ & $60-99 \mathrm{mg} / \mathrm{dl}$ \\
\hline Calcium & $8.9 \mathrm{mg} / \mathrm{dl}$ & $8.5-10.5 \mathrm{mg} / \mathrm{dl}$ \\
\hline Albumin & $4 \mathrm{mg} / \mathrm{dl}$ & $3.5-4.9 \mathrm{mg} / \mathrm{dl}$ \\
\hline
\end{tabular}

Table 2. Blood labs

\section{DISCUSSION}

Management of hyperlipidaemia has improved greatly over the last decades. Many clinical trials have been conducted to identify the effect of lipid-lowering agents on long-term morbidity and mortality ${ }^{[1]}$. Lipid-lowering agents found to have side effects where a pharmacological threshold has been studied and reported as well ${ }^{[2,3]}$. It is also well known that combining different anti-hyperlipidaemic medication classes increases adverse reactions and side effects ${ }^{[1]}$.

Gemfibrozil is a fibric acid derivative and an effective anti-hypertriglyceridaemic agent, especially in type IV and $\mathrm{V}$ hypertriglyceridaemia. It can be introduced after lifestyle modification measures are initiated. It has been proven to have a significant effect on coronary artery disease and the recurrence of hypertriglyceridaemia-induced acute pancreatitis ${ }^{[4,5]}$. Its mechanism of action is to activate peroxisome proliferator-activated receptor-alpha (PPAR-alpha), which in turn activates lipoprotein lipase (LPL), resulting in a reduction in plasma triglyceride levels ${ }^{[4,6]}$.

Gemfibrozil, like any other drug, can cause side effects. In addition to gastrointestinal disturbance, it is reported to cause dizziness and vertigo, and cardiac adverse reactions like atrial fibrillation in about $1 \%$ of patients. Other uncommon side effects are myalgia, rhabdomyolysis, cholelithiasis and angioedema ${ }^{[7,8]}$. 
As far as we know, gemfibrozil does not have adverse effects on the urinary tract; however, there is a lack of literature about this entity. We conducted a literature search mainly of PubMed, Google Scholar, Scopus and ScienceDirect. We found one article about gemfibrozil enhancing memory in a mouse model of Alzheimer's disease that reported polyuria and anuria in experimental mice ${ }^{[9]}$. Another case report found in Google Scholar reported a case of acute renal failure and interstitial nephritis secondary to metamizole and gemfibrozil where polyuria was reported but secondary to renal tubular acidosis ${ }^{[10]}$. Our patient developed polyuria that stressed him and affected his daily activities which started 2 days after gemfibrozil was started and was ongoing for 2 weeks. He had a Naranjo scale score of 9[11]. We stopped the drug for 1 week, and at follow-up the patient reported his symptoms had completely resolved. Physicians must be aware of such uncommon adverse effects and inform the patient about them as they can affect the patient's quality of life.

\section{REFERENCES}

1. Hendrani AD, Adesiyun T, Quispe R, Jones SR, Stone NJ, Blumenthal RS, et al Dyslipidemia management in primary prevention of cardiovascular disease: current guidelines and strategies World J Cardiol 2016;8(2):201-210. https://www.ncbi.nlm.nih.gov/pmc/articles/PMC4766270/pdf/WJC-8-201.pdf

2. Bitzur R, Cohen H, Kamari Y, Harats D. Intolerance to statins: mechanisms and management. Diabetes Care 2013;36(Suppl 2):S325-S330. https://care.diabetesjournals.org/ content/diacare/36/Supplement_2/S325.full.pdf

3. Ito MK. Long-chain omega-3 fatty acids, fibrates and niacin as therapeutic options in the treatment of hypertriglyceridemia: a review of the literature. Atherosclerosis 2015;242(2):647-656.

4. Bussière-Côté S, Omlin T, de Càssia Pinheiro E, Weber J-M. Gemfibrozil disrupts the metabolism of circulating lipids in bobwhite quails. Comp Biochem Physiol Toxicol Pharmacol 2016;179:137-143. doi:10.1016/j.cbpc.2015.09.011

5. Ghosh A, Rangasamy SB, Modi KK, Pahan K. Gemfibrozil, food and drug administration-approved lipid-lowering drug, increases longevity in mouse model of late infantile neuronal ceroid lipofuscinosis. J Neurochem 2017;141(3):423-435. doi:10.1111/jnc.13987

6. Ito MK. Long-chain omega-3 fatty acids, fibrates and niacin as therapeutic options in the treatment of hypertriglyceridemia: a review of the literature. Atherosclerosis 2015;242(2):647-656. doi:10.1016/j.atherosclerosis.2015.06.012

7. Quintanilla Rodriguez BS, Correa R. Gemfibrozil. Treasure Island (FL): StatPearls Publishing; 2021. https://www.ncbi.nlm.nih.gov/books/NBK545266/?report=printable

8. Haybar H, Goudarzi M, Mehrzadi S, Aminzadeh A, Khodayar MJ, Kalantar M, et al. Effect of gemfibrozil on cardiotoxicity induced by doxorubicin in male experimental rats. Biomed Pharmacother Biomedecine Pharmacother 2019;109:530-535. doi:10.1016/j.biopha.2018.10.101

9. Chandra S, Pahan K. Gemfibrozil, a lipid-lowering drug, lowers amyloid plaque pathology and enhances memory in a mouse model of Alzheimer's disease via peroxisome proliferator-activated receptor a. J Alzheimers Dis Rep 2019;3(1):149-168. doi:10.3233/ADR-190104

10. Martín-Navarro JA. Acute renal failure secondary to interstitial acute nephritis and Fanconi syndrome due to metamizole and gemfibrozil. Nefrologia 2016;36(3):321-323.

11. Adverse drug reaction probability scale (Naranjo) in drug induced liver injury. In: LiverTox: clinical and research information on drug-induced liver injury. National Institute of Diabetes and Digestive and Kidney Diseases; 2012. Accessed 24 March 2021. http://www.ncbi.nlm.nih.gov/books/NBK548069/ 